\title{
Is There a Place for the Mini-Cholecystectomy in the Laparoscopic Cholecystectomy Era?
}

\author{
Alaa Ismail, MD; ${ }^{1}$ Ihab K Merhom, MD; ${ }^{2}$ Wael Omar, MD; ${ }^{3}$ Mohamed Abdel Sattar Abdel Hamid, \\ MD; ${ }^{1}$ Mohamed ElAzazi, MD; ${ }^{1}$ Mostafa Abdelrahman, MD; ${ }^{1}$ Ahmed Esawi, MD; ${ }^{4}$ Mohammad Ahmad \\ Abd-erRazik, MD ${ }^{1}$ \\ ${ }^{1}$ Department of Surgery, Faculty of Medicine, Ain-Shams University, Egypt \\ 2Department of Surgery, Faculty of Medicine, Misr University for Science and Technology, Egypt \\ ${ }^{3}$ Department of Surgery, Faculty of Medicine, Helwan University, Egypt \\ ${ }^{4}$ Nasser Institute for Research and Treatment, Egypt
}

Objective: To evaluate the mini-laparotomy cholecystectomy (MC) and to compare it with the current gold standard laparoscopic cholecystectomy (LC).

Patients and methods: In this prospective study, 1854 consecutive patients with ultrasound proven symptomatic cholelithiasis, were recruited to study two different surgical techniques for cholecystectomy; the MC through a 5-7 cm muscle cutting incision (923 patients) and the 4 ports Laparoscopic technique (931 patients).

Results: The groups were well matched for age and sex and presenting symptoms. The mean durations of surgery in both groups were similar. There was no significant difference in the conversion rates of both procedures. While there was a significant difference between the 2 groups regarding the time of return to normal activity, it was $13.9 \pm 7$ days for $M C$ and $7.6 \pm 6$ days for $L C(p=0.041)$.

Conclusion: There is no superiority of one technique over the other. The $M C$ is a safe procedure in experienced hands, applicable and effective therapeutic option for gallstone disease with comparable outcomes to the laparoscopic approach.

Key words: Mini-cholecystectomy, laparoscopic cholecystectomy, gallbladder.

\section{Introduction}

The cost and disability associated with traditional open cholecystectomy had led to the introduction of new techniques for cholecystectomy, all share the common feature of minimal access surgery and excision of gallbladder, hence eliminating the hazards of gallstone recurrence and the acute inflammation and the consequences of open surgery. The hallmark of minimal access surgical procedures is reduction of the trauma of access without compromising exposure of the operative field. These procedures include the laparoscopic cholecystectomy (LC) and the mini-laparotomy cholecystectomy (MC). However, the LC is considered to be the expensive alternative when compared to the MC, moreover LC has a high start-up cost. ${ }^{1}$

It was thought that the introduction of the LC was in Lyon, France by Philippe Moure in March $1987,{ }^{2}$ but actually the first procedure was done in Böblingen, Germany by Erich Mühe in September $1985 .^{3}$ The procedure has evolved, and rapidly become a popular alternative to the traditional cholecystectomy. The enthusiasm for this approach has arisen from the successful results of many personal experiences and its appealing modern technology, at that time. ${ }^{4}$ ${ }^{6}$ Now, LC is possibly the most frequently procedure performed laparoscopically by general surgeons. ${ }^{7,8}$
The mini-cholecystectomy meant the conventional open technique however the abdominal incision is kept as small as possible. Protagonists of this technique have claimed results comparable to those achieved by laparoscopic access. ${ }^{9-11}$ And was even suggested to be an alternative for the LC if the surgeon had no enough experience with laparoscopy. ${ }^{12}$

The aim of this prospective study was to evaluate the outcome following MC technique, and to assess its safety, applicability, efficacy, and its benefit to the patient. Also comparing it with LC, the current gold standard for gall stone disease management, and investigating whether or not it can achieve the goals of rapid postoperative recovery, with comparable complication risks.

\section{Patients and methods}

This was a prospective study performed over 26 years from January 1995 to January 2021, 1854 patients with ultrasound proven cholelithiasis, were recruited into this study. Surgeries were performed by surgeons who had passed the learning curve and had previous experience with these procedures for more than 100 cases.

Inclusion criteria included patients undergoing cholecystectomy for symptomatic, ultrasoundproven cholelithiasis. Patients excluded were 
those requiring urgent operation for empyema or perforation, those with common bile duct (CBD) stones requiring exploration of the duct and those needing intra operative cholangiography (IOC). Patients with abnormal liver functions, CBD stones and / or dilated CBD evident on ultrasonography were only recruited into the trial if they had a normal magnetic resonant cholangio-pancreatography (MRCP) or had duct clearance or stent inserted on a preoperative endoscopes retrograde cholangiopancreatography (ERCP).

The total number of patients eligible for the study was 1854. Patients were allocated into 2 groups, Group A patients underwent MC, while Group B patients underwent LC. It was difficult to obtain patient agreement for randomization. Selection (sampling) bias was hopefully reduced by including successive patients with matching observables in both groups. Informed consent for cholecystectomy for either operation was signed out by all patients.

All patients received second generation cephalosporins during induction of anesthesia. If the procedure was done for acute cholecystitis antibiotics were continued for 48 hours only or for another extra 24 hours after subsidence of pyrexia. In our study, Venous thromboembolism (VTE) prophylaxis was given to high-risk patients in both groups.

\section{Surgical technique}

Most of the procedures were done under general anesthesia, however selected cases in Group A were done under spinal anesthesia, to suit the general condition of those patients. Some patients had nasogastric intubations during the operation for deflation of the stomach and tubes were removed in theatre at the end of the operation.

In Group A patients, the MC access was through a 5-7 cm right transverse subcostal muscle cutting incision. An illuminated retractor was used for better visualization. Dissection was started on the Calot's triangle, the cystic duct and artery were identified, doubly ligated (with absorbable sutures) and divided. The gallbladder was dissected from its bed using coagulation diathermy starting from the fundus, and hemostasis was secured. Closure of the abdominal wall in layers using continuous sutures. Skin was closed with subcuticular absorbable sutures.

In Group B, the LC was done in the supine position, the head and the right shoulder of the table were tilted up. The scope port was inserted using the open technique, pneumo-peritoneum using carbon dioxide was done via that port. Intra-abdominal pressure was adjusted around $13 \pm 2 \mathrm{mmHg}$. Guided insertion of other 2 to 3 trocars was performed.
Dissection of Calot's triangle was performed using both sharp and blunt dissection. In most of the cases surgeons tried to achieve the critical view of safety proposed by Strasberge. ${ }^{13}$ Cystic artery and duct were identified, clipped, and divided. Gall bladder dissection was performed by diathermy, proceeded anti-grade towards the fundus. The peritoneum was evacuated, and wounds were closed.

Suction or tube drains were inserted at the discretion of the surgeon in the two procedures. Operating time was measured by the nursing staff from the first skin incision to the last suture placement for both techniques. Local anesthetic was infiltrated to the wounds in both groups at the end of surgery.

\section{Postoperative protocol}

Postoperative pain relief was ensured. Oral fluids were started after few hours of the operation and if tolerated, light breakfast was allowed the following morning. Drains were typically removed on the first postoperative day before discharge. Readmission for a complication related to the operation was included in the total postoperative stay. Patients were reviewed at the outpatient clinic, at 1 week and 4 weeks after discharge.

The 2 groups were compared as regards operative time, total hospital stay, readmission, wound problems and other complications and time to return to normal job duties or usual home activities if unemployed.

\section{Data collection}

Preoperative data included patient characteristics (Age, sex, and body mass index (BMI), presenting symptom, positive signs on physical examination, (Biochemical and ultrasonography findings).

The severity of co-morbid diseases was classified according to the American Society of Anesthesiologists (ASA) scoring system. ${ }^{14,15}$ Intra-operative and post-operative findings were collected prospectively. Primary endpoints included hospital stay (from the day of operation to the day of discharge), complications and convalescence (time back to work if employed or full activity if unemployed).

\section{Statistical analysis}

Data were tabulated using Excel 365, Microsoft Corporation, USA. While the statistical analysis was done using SOFA Statistics program, version 1.5.4, Paton-Simpson \& Associates Ltd, Auckland, New Zealand. For parametric (Quantitative) data like age, BMI, duration of surgery, hospital stay and time back to full activities, Student t-test was used. For nonparametric (Qualitative) data such as sex, or developing complications, a Chi-square test $\left(X^{2}\right)$ was used to test whether there is any significant 
difference between the two surgical techniques used. To examine whether or not there is any relation between two parameters e.g., obesity reflected by high BMI value and time to return to normal activity or duration of surgery, Pearson's correlation coefficient ( $r$ ) was computed and tested for significance. The $p$ value was reported to be significant if it was $\leq 0.05$.

\section{Results}

Group A patients $(n=923)$ had undergone MC, while Group B patients $(n=931)$ had undergone LC. The characteristics of the 2 groups of patients were well matched for age, sex, and BMI, (Table 1) and presenting symptoms (Table 2). Endoscopic retrograde cholangio-pancreatography (ERCP) was performed in the 44 jaundiced patients, CBD stones or with gall stone pancreatitis. Afterwards LC or MC was followed within 10 days.

There was no significant difference in the conversion rates of both procedures, (Table $\mathbf{3}$ ). In Group $A$, the MC group, the median incision was $7 \mathrm{~cm}$ (Interquartile range $5-9 \mathrm{~cm}$ ). The incision was extended beyond $10 \mathrm{~cm}$ and the rectus muscle was cut in 52 patients $(5.63 \%)$; the reasons for extension were dense adhesions in 38 patients (73\%), uncontrolled bleeding in 12 cases (23.16\%), presence of accessory duct in a single case $(1.92 \%)$, and common bile duct (CBD) injury in a single case $(1.92 \%)$.

In the LC group, 56 patients (6\%) were converted to open surgery; the cause of conversion was unclear anatomy in 44 cases (78.6\%), uncontrolled bleeding in 9 cases (16\%), presence of accessory duct at the gall bladder bed couldn't be controlled laparoscopically in 2 cases (3.6\%), and accidental CBD injury in a single case $(1.8 \%)$.

The mean durations of surgery in both groups were similar. It was $45 \pm 10.4$ minutes in Group $A$, and $46.9 \pm 12.1$ minutes in Group B. It is to be noted that all conversions in the 2 groups were not included in our calculations for the mean (And SD) because this will bias our results. There was no significant difference of postoperative hospital stay after MC

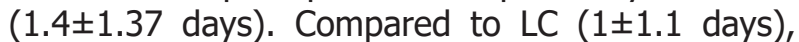
and $\mathrm{p}$ was 0.064 . While there was a significant difference between the 2 groups regarding the time of return to normal activity, it was $13.9 \pm 7$ days for MC and $7.6 \pm 6$ days for LC $(p=0.041)$.

Postoperative complications were presented in Table 3. None of our patients developed clinical evidence of deep venous thrombosis (DVT).

Table 4 showed the correlation coefficient between BMI and duration of surgery, hospital stay and convalescence. This was done to examine whether there is any association between BMI and these parameters. It is to be noted that this was tested only for the MC group. The correlation coefficient ( $r$ ) was only positive between BMI and operative time.

Data from the MCgroup were compared together after being classified according to the BMI into BMI>25 $\mathrm{kg} / \mathrm{m}^{2}$ and $\mathrm{BMI}<25 \mathrm{~kg} / \mathrm{m}^{2}$. There is a tendency that patients with $B M I<25 \mathrm{~kg} / \mathrm{m}^{2}$ had less complications and shorter duration of surgery. Hospital stay and convalescence were not significantly different in the 2 subgroups. The rate of conversion to conventional surgery ends to be less among the $B M I<25$.

Table 1: Patient characteristics

\begin{tabular}{rccc}
\hline & $\begin{array}{c}\text { MC } \\
(\mathbf{n = 9 2 3 )}\end{array}$ & $\begin{array}{c}\text { LC } \\
\text { (n= 931) }\end{array}$ & P \\
\hline Age (years) & $46.6 \pm 8.9$ & $47.1 \pm 10.5$ & $\S 0.632$ \\
Sex (M/F) & $202 / 721$ & $408 / 723$ & $\$ 0.812$ \\
BMI (kg/m $\left.\mathbf{m}^{2}\right)$ & $28 \pm 4.3$ & $28.5 \pm 5.2$ & $\times 0.742$ \\
\hline
\end{tabular}

M: Male, F: Female, BMI: Body mass index, $x$ : Student $t$ test. $\S: ~ x 2$ test.

Table 2: Presenting symptoms, (Percentage between brackets)

\begin{tabular}{lcc}
\hline & $\begin{array}{c}\text { MC } \\
(\mathbf{n = 9 2 3 )}\end{array}$ & $\begin{array}{c}\text { LC } \\
\text { (n)31) }\end{array}$ \\
\hline Biliary colic & $587(63.6 \%)$ & $589(63.3 \%)$ \\
Vague abdominal pain & $126(13.6 \%)$ & $129(13.8 \%)$ \\
Dyspepsia & $179(19.4 \%)$ & $180(19.3 \%)$ \\
Jaundice & $19(2.1 \%)$ & $25(2.7 \%)$ \\
Pancreatitis & $12(1.3 \%)$ & $8(0.9 \%)$ \\
\hline
\end{tabular}


Table 3: Conversions to classical surgery and postoperative complications

\begin{tabular}{lccc}
\hline & $\begin{array}{c}\text { MC } \\
\text { (n= 923) }\end{array}$ & LC & p \\
\hline Conversion to classical O.S. & $52(5.63 \%)$ & $56(6 \%)$ & $\S 0.132$ \\
Complications & $53(5.74 \%)$ & $48(5.15 \%)$ & $\S 0.651$ \\
W. infection & $47(5 \%)$ & $40(4.3 \%)$ & $\S 0.485$ \\
Minor BD inj. & $4(0.4 \%)$ & $5(0.5 \%)$ & $\S 0.748$ \\
Major BD inj. & $2(0.21 \%)$ & $3(0.32 \%)$ & $\S 0.661$ \\
\hline
\end{tabular}

O.S.: Open Surgery, W: Wound, BD inj.: Bile duct injury. §: x2 test.

Table 4: Correlation between BMI and duration of surgery, hospital stay and time of convalescence (MC group only)

\begin{tabular}{lcc}
\hline Correlation Parameter & Pearson's correlation $(\mathbf{r})$ & Significance \\
\hline Duration of surgery & 0.44 & $\mathrm{~S}$ \\
Hospital stays & 0.02 & $\mathrm{P} 0.01$ \\
Convalescence & 0.17 & $\mathrm{NS}$ \\
\hline
\end{tabular}

S: Significant, NS: Non-significant.

\section{Discussion}

We are in the era of minimal access surgery. The access may be minimal, but the surgery and the potential for complications are major. The philosophy of minimal access surgery is to diminish the trauma of access, without compromising exposure of the operative field of interest. Its chief benefits include enhanced recovery with early return to complete activity or work; ${ }^{6}$ beside diminished cost of therapy due to a reduced hospital stay.

The objectives of minimal access surgery can be achieved by laparoscopic and to a lesser extent by the MC. Earlier studies have advised that laparoscopy is better than conventional open cholecystectomy, ${ }^{5,16}$ however, the patient benefits of the LC over the MC haven't been clearly proven. Minilaparotomy cholecystectomy is feasible in most of the patients and is associated with briefer hospital stay and quicker recovery than conventional open cholecystectomy; it can be done through either a midline or a transverse incision. ${ }^{17}$

The present study does not compare LC with MC done via a long subcostal nor a vertical incision. We performed a transverse subcostal incision that gives a direct exposure of the triangle of Calot's.

\section{Conversion rate and complications}

There was no significant difference in the conversion rate between the 2 techniques. Our value for laparoscopic approach was $6 \%$ which is lower than that reported in 3 large series of LC from the United Kingdom (12\%, $15 \%$ and 17\%). ${ }^{10,18,19}$

The surgeons in our study convert to open surgery if they thought that the safety of the dissection was in doubt. The surgeons must keep in mind that 5 to $10 \%$ of cholecystectomies cannot be safely performed laparoscopically, and if a satisfactory exposure of the cystic duct cannot be obtained without compromising the lumen of CBD, the exposure should be converted to an open procedure. ${ }^{20,21}$

For the MC, 52 patients (5.63\%) required incision more than $7 \mathrm{~cm}$; the reasons were dense adhesions and unclear anatomy, bleeding, and bile duct injuries. One should have a low threshold for extension of the wound with muscle cutting and performance of operative cholangiography if the anatomy is not clear or adhesions are dense, and the surgeon should not be struggling to complete the procedure. The safety of the patient should be the paramount concern of the surgeon and conversion in either procedure should not be considered as a failure.

There was no significant difference with complications in our study being $5.15 \%$ in LC and $5.74 \%$ in MC group. Wound infection was less in the LC group, while bile duct injury was insignificantly more in the LC group. However, the results are unlikely to be representative of the true difference in the complication rates of both procedures and are likely to be high for minilaparotomy and low for laparoscopic approach due to chance and the relatively small sample size especially that in the literature there was weak evidence that mortality and overall complication rates were lower following laparoscopic than open surgery including the MC technique. 22,23 Only large-scale studies can accurately estimate the incidence of complications. For example, if the true difference in bile duct injuries between $\mathrm{LC}$ and $\mathrm{MC}$ was $0.5 \%$ and the rate following open cholecystectomy was $0.5 \%$, a randomized study with $80 \%$ power a detect a difference that is 
statistically significant at the $5 \%$ level would need over 5000 patients in each treatment limb. Such studies cannot be done except as a multi centric study and over a long period that may take up to 10 years and will harbor many confounders.

There is no evidence from the literature that DVT is more in either of the 2 procedures. There is an theoretical increased risk of DVT in laparoscopic group due to increased intra-abdominal pressure in addition to the conventional head up position that increase the tendency for blood to pool in lower limbs. ${ }^{24}$

None of our patients had any evidence of pulmonary complications, although studies in the literature reported better postoperative pulmonary functions and $\mathrm{O}_{2}$ saturation in LC. 25,26 The technique of nonmuscle cutting may have influenced the outcome in the form of less postoperative pain and early ambulation. It is worth mentioning that the level of $\mathrm{PaCO} 2$ was reported to increase during abdominal insufflation because of the $\mathrm{CO}^{2}$ diffusion from the peritoneal cavity. ${ }^{27}$ However, it was reported that at an intra-abdominal pressure of $20 \mathrm{mmHg}$, the $\mathrm{PaCO} 2$ did not significantly increase in patients without complications. ${ }^{28}$ This may be of particular importance in patients with advanced chronic obstructive air way disease (COAD) with as high $\mathrm{PaCO} 2$ as $50 \mathrm{mmHg}$. In this selected group, it may be advisable to avoid the laparoscopic approach and resort to mini cholecystectomy.

We excluded patients needed intra-operative cholangiography. The routine IOC is a timeconsuming technique, demanding more personnel in the operation theater to control the bulky machine, with radiation exposure risk for the medical staff and the patient himself. ${ }^{29}$ Moreover it's not associated with lower rates of bile duct injuries. ${ }^{30}$ While other forms of cholangiography like the indocyanine green cholangiography, was reported to make the surgery easier, ${ }^{31}$ and was recommend to be used routinely.

The duration of surgery was slightly higher in the LC group but with no statistical significance, some studies had reported longer time with the LC if compared with MC. .11,32 $^{2}$

\section{Hospital stays}

In the literature, there was a wide variation of hospitalization. The minimum postoperative hospital stays reported were 2.1 days for MC and 1.8 days for $L C$, and the maximum stays ranged 4 day for MC and 3 days for LC. $22,33,34$ Only few studies reported median postoperative hospital stay of 1-2 days both for MC and LC, ${ }^{9,35}$ while all other prospective analytical studies reported longer postoperative hospital stay following MC. $33,36,37$ This provided strong evidence that the differences o postoperative hospital stay seen in most of these studies may have arisen because the decision of discharge was taken by patients and clinicians who were aware which type of surgery the patient had received.

In this study, there was no significant difference of hospital stay between our study groups, but if the conversions were included, there would be a trend towards a shorter hospital stay for LC group. We tried to eliminate this bias by informing patients that MC was a new operation that would result in early discharge. However, this might have only removed bias arising from the patients and not the ward staff.

\section{Convalescence improvement \\ and \\ symptomatic}

There was a longer convalescent time for MC patients, with a statistically significant difference (13 vs 7 days for LC). Convalescence in our study was considered complete when the patient was able to perform all the usual home activities, if unemployed, or his/her full work. Most of previous analytical studies reported that laparoscopic patients returned to normal activity sooner than patients who had undergone MC. ${ }^{35-38}$

The symptomatic benefit was similar in both groups. Response rates varied between $70 \%$ and $97 \%$. The findings from the studies including ours were consistent. They reported that there was no difference in the symptomatic relief resulting from either procedure. ${ }^{36,39,40}$ Although the MC had comparable surgical results with the LC, but it had slightly worse short-term quality of life if compared to LC. ${ }^{41}$ Studies had confirmed that the long-term outcomes of both techniques are similar. ${ }^{42}$

\section{Correlation between variables}

Correlation between BMI and duration of surgery was $0.44(\mathrm{P}<0.00 \mathrm{l})$ for $\mathrm{MC}$ indicating a positive association between both parameters, i.e. There was a significant evidence that patients with BMI more than $25 \mathrm{~kg} / \mathrm{m}^{2}$ tend to have a longer operative time than lean people. On the other hand, there was no correlation between BMI and hospital stay or convalescence time. In the literature, there was also a weak but significant association between BMI and operative time in patients who had laparoscopically completed operations.

\section{Conclusion}

This study has shown that MC is a safe procedure in experienced hands, applicable and effective therapeutic option for gallstone disease with comparable outcomes to the laparoscopic approach in terms of recovery, hospital stay. Surgeons should 
try applying the minimally invasive approaches but not on the expense of safety. As regard the training for the MC, we recommend that the junior surgeon should have adequate experience in the conventional open method, then can start training himself on the smaller incision until he reaches the $5-7 \mathrm{~cm}$ incision. Mini-cholecystectomy is recommended in places where no laparoscopic equipment or training is available or when there is a contraindication to the laparoscopic approach as advanced COAD or extensive adhesions.

\section{References}

1. Vagenas K, Spyrakopoulos P, Karanikolas M, et al: Mini-laparotomy cholecystectomy versus laparoscopic cholecystectomy: Which way to go? Surg Laparosc Endosc Percutaneous Tech. 2006; 16(5): 321-324. doi:10.1097/01. SLE.0000213720.42215.7B.

2. Perissat J, Vitale GC: Laparoscopic cholecystectomy: gateway to the future. $\mathrm{Am}$ J Surg. 1991; 161(3): 408. doi:10.1016/00029610(91)90609-h.

3. Reynolds $\mathrm{W}$ : The first laparoscopic cholecystectomy. JSLS J Soc Laparoendosc Surg. 2001; 5(1): 89-94.

4. Dubois F, Icard $P$, Berthelot $G$, Levard $H$ : Coelioscopic cholecystectomy: Preliminary report of 36 cases. Ann Surg. 1990 ;211(1): 6062. doi:10.1097/00000658-199001000-00010.

5. Gadacz TR, Talamini MA: Traditional versus laparoscopic cholecystectomy. Am J Surg. 1991; 161(3): 336-338. doi:10.1016/00029610(91)90591-Z.

6. Larson GM, Vitale GC, Casey J, et al: Multipractice analysis of laparoscopic cholecystectomy in 1,983 patients. Am J Surg. 1992; 163(2): 221226. doi:10.1016/0002-9610(92)90105-z.

7. Alexander HC, Bartlett AS, Wells CI, et al: Reporting of complications after laparoscopic cholecystectomy: a systematic review. HРВ. 2018; 20(9): 786-794. doi:10.1016/]. HPB.2018.03.004.

8. Brunt LM, Deziel DJ, Telem DA, et al: Safe Cholecystectomy Multi-society Practice Guideline and State of the Art Consensus Conference on Prevention of Bile Duct Injury During Cholecystectomy. Ann Surg. 2020; 272(1): 3-23. doi:10.1097/SLA.0000000000003791.

9. Saltzstein EC, Mercer LC, Peacock JB, Dougherty SH: Outpatient open cholecystectomy. Surg Gynecol Obstet. 1992; 174(3): 173-175.

10. Majeed AW, Troy G, Nicholl JP, et al: Randomised, prospective, single-blind comparison of laparoscopic versus small-incision cholecystectomy. Lancet. 1996; 347(9007): 989-994. doi:10.1016/S0140-6736(96)901439.

11. Ros A, Gustafsson L, Krook H, et al: Laparoscopic Cholecystectomy Versus Mini-Laparotomy Cholecystectomy: A Prospective, Randomized, Single-Blind Study. Ann Surg. 2001; 234(6). doi:10.1097/00000658-200112000-00005.

12. Almahjoub A, Elfaedy $\mathrm{O}$, Mansor $\mathrm{S}$, et al: A retrospective multicentric study among patients operated in some Eastern Libyan hospitals. Turkish J Surg. 2019; 35(3): 185-190. doi:10.5578/TURKJSURG.4208.

13. Strasberg SM, Sanabria JR, Clavien PA: Complications of laparoscopic cholecystectomy. Can J Surg. 1992; 35(3): 275-280.

14. Owens WD, Felts JA, Spitznagel EL: ASA physical status classifications: a study of consistency of ratings. Anesthesiology. 1978; 49(4): 239-243. doi:10.1097/00000542-197810000-00003.

15. American Society Of anesthesiologists: ASA Physical Status Classification System | American Society of Anesthesiologists (ASA). Standars and Guidelines. Published December 13, 2020. https://www.asahq.org/standards-andguidelines/asa-physical-status-classificationsystem.

16. Neugebauer $E$, Troidl $H$, Spangenberger $W$, Dietrich A, Lefering R: Conventional Versus laparoscopic cholecystectomy and the randomized controlled trial. Br J Surg. 1991; 78(2): 150-154.

17. Ledet WP: Ambulatory cholecystectomy without disability. Arch Surg. 1990; 125(11): 1434-1435. doi:10.1001/archsurg.1990.01410230028004.

18. Fullarton GM, Bell G: Prospective audit of the introduction of laparoscopic cholecystectomy in the west of Scotland. West of Scotland Laparoscopic Cholecystectomy Audit Group. Gut. 1994; 35(8): 1121-1126. doi:10.1136/ gut.35.8.1121.

19. Steele RJ, Marshall K, Lang M, Doran J: Introduction of laparoscopic cholecystectomy in a large teaching hospital: independent audit of the first 3 years. Br J Surg. 1995; 82(7): 968971. doi:10.1002/bjs. 1800820736.

20. Crist DW, Gadacz TR: Laparoscopic anatomy of the biliary tree. Surg Clin North Am. 1993; 73(4): 785-798. doi:10.1016/s0039-6109(16)46085-8.

21. Diamantis T, Tsigris C, Kiriakopoulos A, et al: Bile duct injuries associated with laparoscopic and open cholecystectomy: An 11-year experience 
in one institute. Surg Today. 2005; 35(10): 841845. doi:10.1007/S00595-005-3038-Z.

22. Deziel DJ, Millikan KW, Economou SG, et al: Complications of laparoscopic cholecystectomy: a national survey of 4,292 hospitals and an analysis of 77,604 cases. Am $\boldsymbol{J}$ Surg. 1993; 165(1): 9-14. doi:10.1016/s00029610(05)80397-6.

23. Roslyn JJ, Binns GS, Hughes EF, et al: Open Cholecystectomy: A Contemporary Analysis of 42, 474 Patients - Northwestern Scholars. Ann Surg. 1993; 218: 129-137.

24. Bromley LM: Does minimal access cholecystectomy require simple anaesthesia? Clin Risk. 1995; 1(1): 18-21. doi:10.1177/135626229500100104.

25. Karayiannakis AJ, Makri GG, Mantzioka A, et al: Postoperative pulmonary function after laparoscopic and open cholecystectomy. $\boldsymbol{B r} \boldsymbol{J}$ Anaesth. 1996; 77(4): 448-452. doi:10.1093/ $\mathrm{bja} / 77.4 .448$.

26. Hasukie Š, Mešićć $D$, Dizdarević $E$, et al: Pulmonary function after laparoscopic and open cholecystectomy. Surg Endosc Other Interv Tech. 2002; 16(1): 163-165. doi:10.1007/S00464001-0060-0.

27. Ivankovich $A D$, Miletich $D J$, Albrecht RF, et al: Cardiovascular effects of intraperitoneal insufflation with carbon dioxide and nitrous oxide in the dog. Anesthesiology. 1975; 42(3): 281-287. doi:10.1097/00000542-19750300000008.

28. Wittgen $\mathrm{CM}$, Andrus $\mathrm{CH}$, Fitzgerald $\mathrm{SD}$, et al: Analysis of the Hemodynamic and Ventilatory Effects of Laparoscopic Cholecystectomy. Arch Surg. 1991; 126(8): 997-1001. doi:10.1001/ ARCHSURG.1991.01410320083011.

29. Ishizawa $T$, Bandai $Y$, Ijichi $M$, et al: Fluorescent cholangiography illuminating the biliary tree during laparoscopic cholecystectomy. Br J Surg. 2010; 97(9): 1369-1377.

30. Vezakis A, Davides D, Ammori BJ, et al: Intraoperative cholangiography during laparoscopic cholecystectomy. Surg Endosc 2000 1412. 2014; 14(12): 1118-1122. doi:10.1007/ S004640000076.

31. Abd-erRazik MA, Abdel Hamid MAS: Indocyanine Green Fluorescent Cholangiography During Laparoscopic Cholecystectomy, Ain-Shams University and Egypt's Initial Experience-A Case Report. Ain-Shams J Surg. 2020; 13(2): 112-
114. doi:10.1055/s-0043-123937.

32. Harju J, Juvonen $P$, Eskelinen $M$, et al: Minilaparotomy cholecystectomy versus laparoscopic cholecystectomy. Surg Endosc Other Interv Tech 2006 204. 2006; 20(4): 583586. doi:10.1007/S00464-004-2280-6.

33. Grace PA, Quereshi A, Coleman J, et al: Reduced postoperative hospitalization after laparoscopic cholecystectomy. Br J Surg. 1991; 78(2): 160162. doi: $10.1002 /$ bjs. 1800780209.

34. Olsen DO: Mini-lap cholecystectomy. Am J Surg. 1993; 165(4): 440-443. doi:10.1016/s00029610(05)80937-7.

35. McGinn FP, Miles AJG, Uglow M, etal: Randomized trial of laparoscopic cholecystectomy and minicholecystectomy. Br J Surg. 2005; 82(10): 1374-1377. doi:10.1002/bjs. 1800821027.

36. McMahon AJ, Baxter JN, Anderson JR, et al: Laparoscopic versus minilaparotomy cholecystectomy: a randomised trial. Lancet. 1994; 343(8890): 135-138. doi:10.1016/S01406736(94)90932-6.

37. Barkun JS, Sampalls JS, Fried G, et al: Randomised controlled trial of laparoscopic versus mini cholecystectomy. Lancet. 1992; 340(8828): 1116-1119. doi:10.1016/01406736(92)93148-G.

38. Cuschieri A, Dubois F, Mouiel J, et al: The european experience with laparoscopic cholecystectomy. Am J Surg. 1991; 161(3): 385-387. doi:10.1016/0002-9610(91)90603-B.

39. Mühe E: Long-term follow-up after laparoscopic cholecystectomy: Endoscopy. 1992; 24(9): 754758. doi:10.1055/S-2007-1009119.

40. Jan YY, Chen MF: Laparoscopic Versus Open Cholecystectomy: a Prospective Randomized Study. J Formos Med Assoc. 1993; 92 Suppl 4: S243-9.

41. Rosenmüller $M H$, Thorén Örnberg M, Myrnäs $T$, et al: Expertise-based randomized clinical trial of laparoscopic versus small-incision open cholecystectomy. Br J Surg. 2013; 100(7): 886894. doi:10.1002/bjs.9133.

42. Harju J, Aspinen S, Juvonen $P$, et al: Tenyear outcome after minilaparotomy versus laparoscopic cholecystectomy: A prospective randomised trial. Surg Endosc 2013 277. 2013; 27(7): 2512-2516. doi:10.1007/S00464-0122770-X. 